\title{
APLICAÇÃO DE 1-METILCICLOPROPENO EM BANANA 'PRATA-ANÃ' E SEU EFEITO SOBRE AS SUBSTÂNCIAS PÉCTICAS E ENZIMAS PECTINOLÍTICAS
}

\author{
Application of 1-Methylcyclopropene on bananas cv. \\ 'Prata-Anã' and its effect upon pectic substances and pectinolytic enzymes
}

\author{
Alenir Naves de Sales ${ }^{1}$, Neide Botrel ${ }^{2}$, Ana Helena Romaniello Coelho ${ }^{3}$
}

\begin{abstract}
RESUMO
No presente estudo, visou-se a verificar o efeito do 1-metilciclopropeno (1-MCP), um produto bloqueador do etileno, sobre a qualidade da banana 'Prata-Anã'. Os frutos foram colhidos no estádio de maturação 1, que corresponde ao estádio de cor da casca verde e separados em grupos, de acordo com os dois diferentes calibres. Cada parcela foi composta por um buquê de seis dedos, com quatro repetições para cada tratamento. Foram utilizadas 4 concentrações de 1-MCP: 0, 30, 60 e 90 ng. $\mathrm{g}^{-1}$, preparadas a partir do produto comercial $(0,14 \% \mathrm{~m} / \mathrm{m}$ de de i. a). Os frutos, exceto os do grupo controle, foram armazenados por 20 dias a $12^{\circ} \mathrm{C}$, seguidos de climatização com $1,5 \%$ da mistura etil 5 a $17^{\circ} \mathrm{C}$ durante 24 horas, após o que foram transferidos para ambiente comum $\left(23^{\circ} \mathrm{C}\right)$ por 93 horas, antes de serem submetidos às análises químicas e bioquímicas. Frutos tratados com 1-MCP, especialmente na dose de $60 \mathrm{ng} \cdot \mathrm{g}^{-1}$, apresentaram reduzidos teores de pectina solúvel, porcentagens de solubilização de pectinas e menores atividades das enzimas pectinametilesterase (PME) e poligalacturonase (PG) que os frutos não tratados. O uso do 1-MCP, nas concentrações utilizadas, não impediu que o processo de amadurecimento evoluísse normalmente após a climatização dos frutos.
\end{abstract}

Termos para indexação: Musa acuminata, amadurecimento de banana, solubilização de pectinas.

\begin{abstract}
The effects of 1 methylciclopropene (1-MCP), an ethylene blocker compound, on the quality of "Prata-Anã" bananas were investigated. The fruits were harvested in maturation stage 1, corresponding to the green skin color stage and separated into groups according to the two different calibers. Each plot was made up of a bouquet of six fingers with four replicates per each treatment. Four concentrations of $1-\operatorname{MCP}\left(0,30,60\right.$ and $\left.90 \mathrm{ng} \cdot \mathrm{g}^{-1}\right)$ were tested, with a powder-formulation at the concentration of $0.14 \%$ of active ingredient being used. The fruits were stored for a period of 20 days at the temperature of $12^{\circ} \mathrm{C}$. After this step, with the exception of the control group, climatization of the fruits was carried out with $1.5 \%$ of the mixture ethyl and temperature of $17^{\circ} \mathrm{C}$ for 24 hours. The fruits were placed at room temperature $\left(23^{\circ} \mathrm{C}\right)$ for 93 hours and evaluated in their chemical and biochemical features. The total and soluble pectin contents and the pectin solubilization's percentage were evaluated. 1-MCP-treated fruits, particularly at the concentration of $60 \mathrm{ng} . \mathrm{g}-1$, showed reduced contents of soluble pectin, percentages of pectin solubilization and poorer activities of the pectinmethylesterase (PME) and polygalacturonase (PG) enzymes than non-treated fruits. Use of 1-MCP at the concentrations utilized did not prevent the maturing process evolving normally after fruit acclimatization Therefore, applications of 1-MCP may extend post-harvest life of 'Prata Anã' banana, without altering the final quality of the product.
\end{abstract}

Index terms: Musa acuminata, ripening of banana, pectin solubilization.

(Recebido para publicação em 6 de agosto de 2002 e aprovado em $1^{\circ}$ de novembro de 2002)

\section{INTRODUÇÃO}

O Brasil é o segundo maior produtor mundial de banana, com 6,8 milhões de toneladas anuais (AGRIANUAL, 2001), e o Estado de Minas Gerais tem uma participação significativa, com destaque para a cultivar 'Prata', tanto na produção quanto na comercialização. Todavia, a susceptibilidade à senescência, aliada à sua elevada sensibilidade a danos mecânicos, limitam o comércio do fruto a locais próximos das áreas de produção, principalmente quando não se utiliza cadeia de frio.

\footnotetext{
1. Mestre em Ciência dos Alimentos - Departamento de Ciência dos Alimentos da Universidade Federal de Lavras/UFLA - Caixa Postal 37 - $37200-000$ Lavras, MG.

2. Dra., Pesquisadora - EMBRAPA Agroindústria de Alimentos - 23020-470 - Rio de Janeiro/RJ. nbotrel@ctaa. embrapa.br

3. Professora, Doutora - DCA/UFLA. anahelena@ufla.br
} 
A banana, como fruto climatérico, é caracterizada por um aumento na produção de etileno no início da maturação (MARRIOTT e PALMER, 1980). Por esse motivo, seu tempo de prateleira é reduzido pela evolução do etileno (JIANG et al., 1999). Em recentes anos, agentes efetivos para bloquear os receptores de etileno têm sido descobertos, prometendo, mediante bloqueio na ação do etileno, um novo modo de controlar o amadurecimento, a senescência e outras respostas ao etileno. Recentemente, em estudos tem-se demonstrado que um novo gás, o 1-metilciclopropeno (1-MCP), tem um efeito inibidor na ação do etileno (SEREK e SISTER, 1994; SEREK et al., 1995).

Os efeitos do 1-MCP sobre frutos e vegetais incluem o atraso da senescência em morangos (KU e WILLS, 1999a) e broócolis (KU e WILLS, 1999b) e a inibição do desverdecimento em laranjas (PORAT, 1999). Macnish et al. (1998), citados por Harris (2000), demonstraram uma extensão de 4,4 vezes na vida de prateleira de bananas 'Cavendish' a $20^{\circ} \mathrm{C}$, tratadas com $15 \mu 1.1^{-1}$ de 1 -MCP por 12 horas e, então, expostos a 100 $\mu 1.1^{-1}$ de etileno por 12 horas, comparados com frutos não tratados com 1-MCP, mas similarmente expostos ao 1-MCP. Neste estudo, nenhuma referência foi feita à maturidade do fruto, o que poderia ter um efeito interativo sobre o amadurecimento, já que a sensitividade ao etileno aumenta com o aumento da idade fisiológica das bananas (LIU, 1976).

O 1-MCP é um produto inovador que bloqueia a ação do etileno em plantas e frutos armazenados. Age pela fixação preferencial ao receptor de etileno, bloqueando, desse modo, os efeitos do etileno procedente de fontes endógenas e exógenas, sendo eficaz mesmo em concentrações extremamente baixas. A maioria das respostas ao 1-MCP pode ser revertida pelo etileno, após decorrência de um determinado período de tempo, pela geração de novos receptores de etileno (ROHM e HAAS, 2002).

Existem excelentes benefícios do 1-MCP para certas plantas ornamentais e uma boa adoção desse produto pela indústria de flores. Para maçãs, o 1-MCP tem a habilidade de aumentar a manutenção da firmeza do fruto durante o armazenamento e também reduzir a incidência de algumas desordens de armazenamento. $\mathrm{O}$ uso do 1-MCP pode permitir uma redução do uso de certos produtos químicos para o controle dessas desordens. Como outras tecnologias de armazenamento, o 1MCP deve ser visto como um coadjuvante, ao lado da manutenção da temperatura e da umidade relativa apropriadas para o produto (BLANKENSHIP, 2001).
Apesar dos poucos trabalhos envolvendo 1-MCP e banana, de acordo com o Boletim Técnico da Agrofresh Inc, o 1-MCP provou exercer um importante efeito sobre o amadurecimento desse fruto. Em estudos, tem sido demonstrado que concentrações tão baixas como $100 \mathrm{ng} \cdot \mathrm{g}^{-1}$ irão quase dobrar os dias para a obtenção da gradação de cor 6 em banana verde 'Cavendish'. O 1-MCP, em combinação com embalagem de atmosfera modificada com níveis mais baixos de oxigênio, aumentou a vida verde das bananas por 6 semanas (JIANG et al., 1999).

A associação do armazenamento em baixa temperatura $\left(13^{\circ} \mathrm{C}\right)$ com a aplicação de $1-\mathrm{MCP}$ a $30 \mathrm{ng} / \mathrm{g}$ proporcionou a manutenção do estado de comercialização dos frutos de banana 'Prata' por até 21 dias (ROHM e HAAS, 2002).

A aplicação de 1-MCP em banana 'Prata' por 12 horas, em doses de 30 a $90 \mathrm{ng}^{-1}{ }^{-1}$, proporcionou, respectivamente, manutenção da textura das frutas e condições de comercialização de até oito e doze dias. Jiang et al. (1999), avaliando o efeito do 1-MCP em combinação com sacos de polietileno no amadurecimento de bananas, concluíram que o 1-MCP é um potencial antagonista à ação do etileno. Segundo os mesmos autores, a utilização do 1-MCP pode ser destacada como uma tecnologia fácil para o transporte de frutos verdes a longas distâncias.

As substâncias pécticas encontram-se depositadas principalmente na parede celular, atuando como material cimentante, sendo responsáveis pelas mudanças de textura dos frutos. As pectinas em frutos encontram-se sob diferentes formas, caracterizadas por diferentes solubilidades. A protopectina é uma forma insolúvel em água que, por hidrólise parcial, produz ácidos pectínicos ou ácidos pécticos (solúveis). A decomposição das moléculas poliméricas, como protopectinas, celuloses, hemiceluloses e amido, amacia as paredes celulares, pois diminui a força coesiva que mantém as células unidas (CHITARRA e CHITARRA, 1990; KOJIMA et al., 1994).

Um decréscimo na protopectina e na pectina total é observado durante o amadurecimento, paralelamente ao aumento das pectinas solúveis na polpa da banana (VILAS BOAS, 1995). Na polpa de bananas, a protopectina insolúvel diminui de $0,5 \%$ a aproximadamente $0,3 \%$, enquanto a pectina solúvel em água aumenta em uma quantidade equivalente (MARKOVIC et al., 1975).

Um grande número de enzimas tem participação na degradação biológica das substâncias pécticas, em-

Ciênc. agrotec., Lavras, v. 28, n. 3, p. 479-487, maio/jun., 2004 
bora algumas não sejam bem estudadas. Entre elas, as mais importantes são as pectinametilesterases (PME) e as poligalacturonases (PG) (FONSECA, 1974).

O amaciamento que pode ocorrer durante a solubilização da pectina, que ocorre no amadurecimento do fruto, normalmente é atribuído à hidrólise de ligações glicosídicas na pectina por poligalacturonase (PG) (PRESSEY e AVANTS, 1982; HUBER, 1983). Segundo os mesmos autores, a ausência de PG no fruto imaturo, seu aparecimento próximo ao início da maturação e o incremento na sua atividade com liberação de pectina solúvel na maturação sugerem que ela esteja implicada na solubilização de pectina. Em virtude do aumento dos níveis de pectina solúvel durante o amadurecimento da banana, o envolvimento de PG, assim como de PME, nos processos degradativos da pectina, pode ser sugerido (LIZADA, 1990).

\section{MATERIAL E MÉTODOS}

Utilizou-se banana 'Prata-Anã' cultivada em Janaúba - MG, no estádio de maturação 1, que corresponde ao estádio de cor da casca verde, com comprimento médio em torno de $18 \mathrm{~cm}$. Os frutos foram separados em dois grupos, baseando-se no calibre (Grupo 1: 33-34 mm e Grupo 2: 36-38 mm). Após a colheita, os frutos foram transportados a 14 ${ }^{\circ} \mathrm{C}$ durante 24 horas para o laboratório de PósColheita da Embrapa - Agroindústria de Alimentos, no Rio de Janeiro, RJ.

Utilizaram-se três concentrações de 1-MCP: 30, 60 e $90 \mathrm{ng} \cdot \mathrm{g}^{-1}$, preparadas a partir do produto comercial Ethylbloc a $0,14 \%$ de i.a., usando-se água destilada para se obter o produto gasoso. A aplicação dos tratamentos foi feita em caixas de PVC preto, hermeticamente fechadas, medindo $46 \times 50 \times 81$ $\mathrm{cm}$, com temperatura interna de $12^{\circ} \mathrm{C}$, durante 12 horas. Após o tratamento, os frutos foram retirados da caixa e colocados em câmara fria $\left(12^{\circ} \mathrm{C}\right.$ por 20 dias com U. R. de $90 \% \pm 3 \%$ ).

A climatização dos frutos foi feita em microcâmaras a $17^{\circ} \mathrm{C}$, aplicando-se etil 5 a $1,5 \%$ durante 24 horas. Em seguida, os frutos foram submetidos a temperaturas mais elevadas ( cerca de $23^{\circ} \mathrm{C}$, para facilitar o amadurecimento.

As amostras, tomadas para avaliações bioquímicas, foram congeladas em nitrogênio líquido e transportadas em caixas de isopor e numa viatura com ar condi- cionado para o laboratório de pós-colheita da Universidade Federal de Lavras, distante cerca de $600 \mathrm{Km}$ da Embrapa do Rio de Janeiro.

Avaliaram-se os teores de pectina total, solúvel, a porcentagem de solubilização da pectina e a medida da atividade das enzimas pectinametilesterase e poligalacturonase.

\section{Pectina solúvel e total (mg de ácido poligalac- turônico/100g polpa)}

As pectinas, total e solúvel, foram extraídas segundo técnica preconizada por McCready e McComb (1952) e dosadas de acordo com Bitter e Muir (1962). A leitura foi realizada em espectrofotômetro Varian Cary 50 Probe, com sistema computadorizado.

\section{Pectinametilesterase (PME) (nmol. $\mathrm{g}^{-1} \cdot \mathrm{min}^{-1}$ )}

A extração e o doseamento foram feitos pela técnica empregada por Ratner et al. (1969). Uma unidade de atividade de pectinametilesterase foi considerada como sendo a quantidade de enzima capaz de catalisar a desmetilação de pectina, correspondente a um nanomol de $\mathrm{NaOH}$ por minuto, nas condições do ensaio. Os resultados foram expressos em nmol g${ }^{-1} \mathrm{~min}^{-1}$.

\section{Poligalacturonase (PG): $\mathrm{nmol}_{\mathrm{g}} \mathrm{g}^{-1} \cdot \mathrm{min}^{-1}$}

Extraída segundo os métodos descritos por Pressey e Avants (1973) e Jen e Robinson (1984). A unidade de atividade de poligalacturonase foi considerada como sendo a quantidade de enzima capaz de catalisar a formação de um nmol de grupos redutores por minuto, nas condições do ensaio. Os resultados foram expressos em nmol g ${ }^{-1} \min ^{-1}$.

\section{Delineamento experimental}

Utilizou-se o delineamento experimental inteiramente casualizado (DIC), em esquema fatorial $4 \times 2$, sendo quatro concentrações de 1-MCP $(0 ; 30 ; 60$ e 90 ng. $\left.\mathrm{g}^{-1}\right)$ e dois calibres de frutos (menor e maior), com quatro repetições, perfazendo um total de 32 parcelas experimentais, sendo cada parcela composta por um buquê de seis dedos.

Quando ocorreram diferenças significativas em resposta às concentrações de 1-MCP, utilizou-se análise de regressão para o estudo das variáveis em função das concentrações.

Para a variável calibre, quando houve diferença significativa, foi realizado o teste de F. 


\section{RESULTADOS E DISCUSSÃO}

\section{Pectinas}

A pectina total mostrou-se significativamente afetada apenas pelo fator calibre. Os frutos com calibre menor apresentaram maior média de pectina total (Tabela 1$)$.

TABELA 1 - Valores médios de pectina total (mg de ácido poligalacturônico /100 g de polpa) de bananas 'Prata-Anã' em dois diferentes calibres, climatizadas por 24 horas.

\begin{tabular}{cc}
\hline Calibres & Pectina Total* $^{*}$ \\
\hline Menor & $697.35^{\mathrm{a}}$ \\
Maior & $641.31 \mathrm{~b}$
\end{tabular}

*Médias seguidas de letras distintas diferem entre si pelo teste de $\mathrm{F}(\mathrm{P}<0,01)$.

Israeli e Lahav (1986) e Vilas Boas (1995) observaram um aumento no teor de pectina total durante o amadurecimento de banana 'Prata'; porém, Chitarra (1979), Forsyth (1980) e Tan (1986) observaram decréscimo no teor de pectina total durante o amadurecimento de bananas. Pelo exposto, observase que a pectina total não tem influência decisiva sobre o processo de amadurecimento da banana, pois esse pode ocorrer simultaneamente tanto com o aumento como pelo decréscimo dos teores de pectina total, bem como com níveis estáveis desses constituintes.

A pectina solúvel mostrou-se significativamente afetada pela interação níveis de 1-MCP e calibres, como também a porcentagem de solubilização.

Os frutos com calibre menor (Figura 1) apresentaram comportamento quadrático, com tendência de menores teores de pectina solúvel até o nível de $60 \mathrm{ng} \cdot \mathrm{g}^{-1}$, concordando perfeitamente com a porcentagem de solubilização (Figura 2). Os frutoscontrole apresentaram maiores valores de pectina solúvel em relação aos frutos tratados com 1-MCP, em todas as concentrações utilizadas, evidenciando a eficiência do produto em restringir a ação do eti- leno e seus efeitos, contribuindo para a manutenção da firmeza. Observou-se tendência linear decrescente nos teores de pectina solúvel em frutos de calibre maior, com o aumento dos níveis de 1-MCP, concordando também com a porcentagem de solubilização. Destacaram-se os níveis de 60 e 90 ng. ${ }^{-1}$ de 1-MCP.

Kojima et al. (1994) observaram um aumento no teor de pectina solúvel durante a maturação da banana 'Prata'. Vilas Boas (1995) obteve resultados semelhantes trabalhando com a mesma cultivar, e o fruto verde apresentou $43 \mathrm{mg} / 100 \mathrm{~g}$, e o maduro, $443 \mathrm{mg} / 100 \mathrm{~g}$. No presente trabalho, à semelhança do que ocorreu nos trabalhos citados acima, nota-se que o 1-MCP retardou a solubilização de pectinas da banana 'Prata-Anã' em todos as concentrações utilizadas, sendo ainda necessário considerar que esses frutos foram climatizados.

\section{Pectinametilesterase (PME) e Poligalacturo- nase (PG)}

Com relação à PME, houve interação significativa entre os fatores estudados.

Na Figura 3 pode-se observar a atividade da PME nos frutos submetidos aos diferentes tratamentos. Nota-se uma maior atividade da enzima no grupo controle, coincidindo com um maior teor de pectina solúvel (Figura 1).

Nos frutos com calibre menor, observou-se uma atividade de PME decrescente, e a 90 ng. ${ }^{-1}$, a atividade foi praticamente insignificante, quando comparada com a atividade dos demais frutos tratados com 1-MCP. Essa atividade de PME é condizente com os menores teores de pectina solúvel até 60 ng. $\mathrm{g}^{-1}$ (Figura 1), demonstrando que, mesmo com a climatização, o processo de amadurecimento dos frutos tratados com 1-MCP foi mais lento que o dos frutos-controle.

Os frutos com calibre maior apresentaram comportamento similar ao dos frutos com calibre menor, divergindo apenas nos níveis de 60 e 90 $\mathrm{ng} \cdot \mathrm{g}^{-1}$, nos quais a atividade da enzima é considerada praticamente insignificante em relação a 0 e 30 $\mathrm{ng} \cdot \mathrm{g}^{-1}$, apesar de ter havido alto teor de pectina solúvel (Figura 1) e alta porcentagem de solubilização (Figura 2) nesses níveis. 


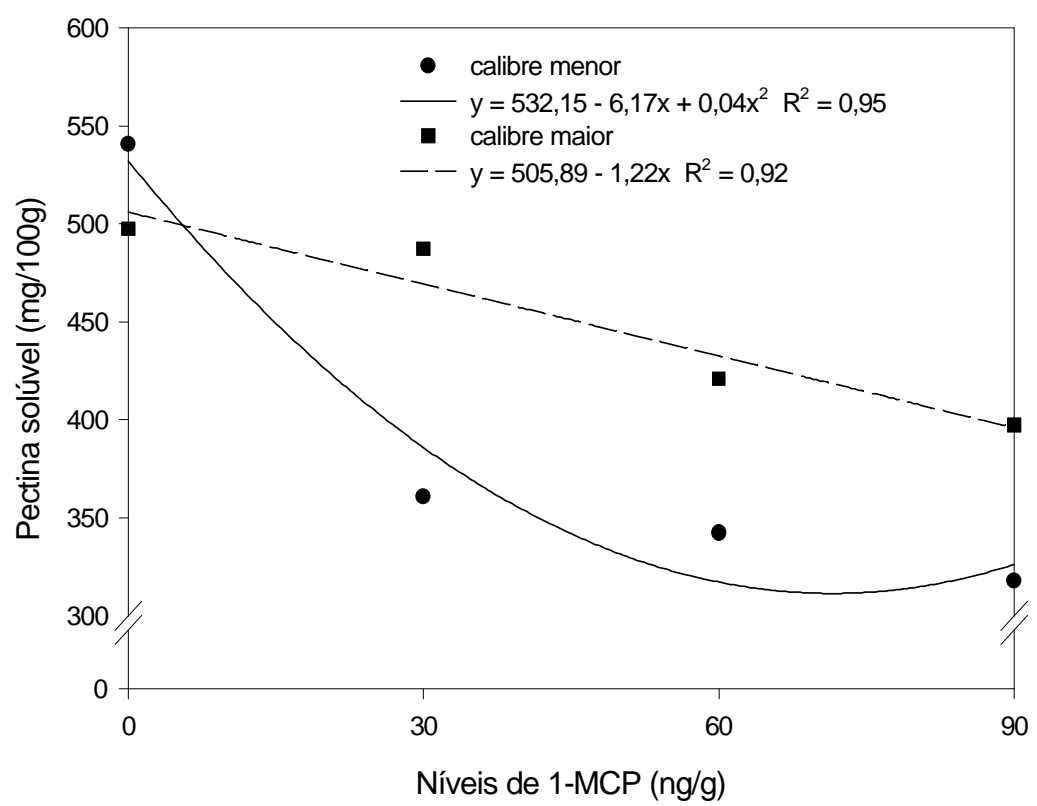

FIGURA 1 - Representação gráfica, equação de regressão e coeficiente de determinação para pectina solúvel de bananas 'Prata-Anã' com calibre maior e calibre menor submetidas a diferentes níveis de 1-MCP, climatizadas por 24 horas.

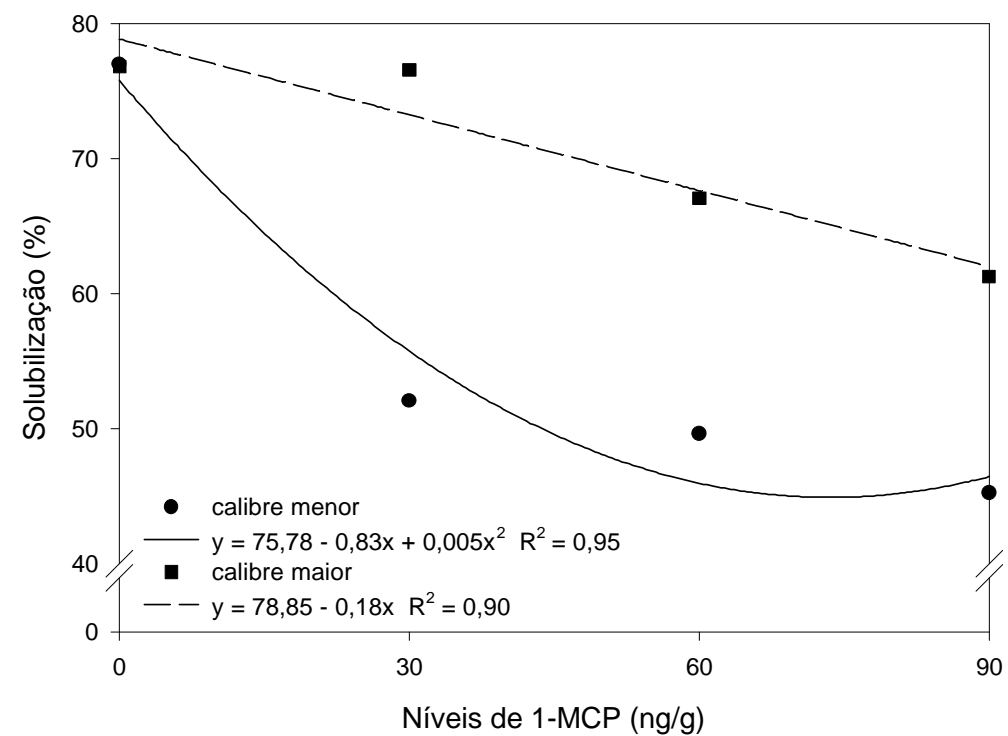

FIGURA 2 - Representação gráfica, equação de regressão e coeficiente de determinação para solubilização de pectinas de bananas 'Prata-Anã' com calibre maior e calibre menor submetidas a diferentes níveis de 1-MCP e climatizadas por 24 horas. 
A solubilização de substâncias pécticas implica o envolvimento das enzimas pectinametilesterase e poligalacturonase nos processos de degradação da pectina (HULTIN e LEVINE, 1965; AHMAD e LABAVITCH, 1980; LIZADA, 1990). Segundo Fennema (1993), essas enzimas são comumente encontradas em frutos tropicais e suas atividades são sempre maiores durante a fase de maturação.

Vilas Boas (1995) observou em banana 'Prata' dois picos de atividade de PME durante a maturação, o que não ocorreu no presente trabalho, no qual os frutos estavam em estádios de maturação não tão distintos quanto os do referido autor, devido à climatização deles.

Com relação à poligalacturonase, também houve interação significativa para níveis de 1-MCP e calibre.
Observa-se na Figura 4 que nos níveis de 30 e 60 ng. $\mathrm{g}^{-1}$, nos dois calibres, a atividade da PG foi menor em relação ao controle.

A partir de $60 \mathrm{ng} \cdot \mathrm{g}^{-1}$, verifica-se um aumento na atividade da enzima, sendo a maior atividade detectada nos frutos tratados com 90 ng. ${ }^{-1}$ de 1MCP.

Não houve relação direta entre a atividade da poligalacturonase e a porcentagem de solubilização de pectinas, já que a concentração de 1 - MCP, que proporcionou a maior atividade da $\mathrm{PG}$, foi a que provocou a menor solubilização. De acordo com Fisher e Bennet (1991), Fry (1995) e Huber (1983), outras enzimas, tais como a $\beta$-galactosidase, $\beta$-1,4 glicanase ou celulase, entre outras, podem provocar a quebra do polímero péctico.

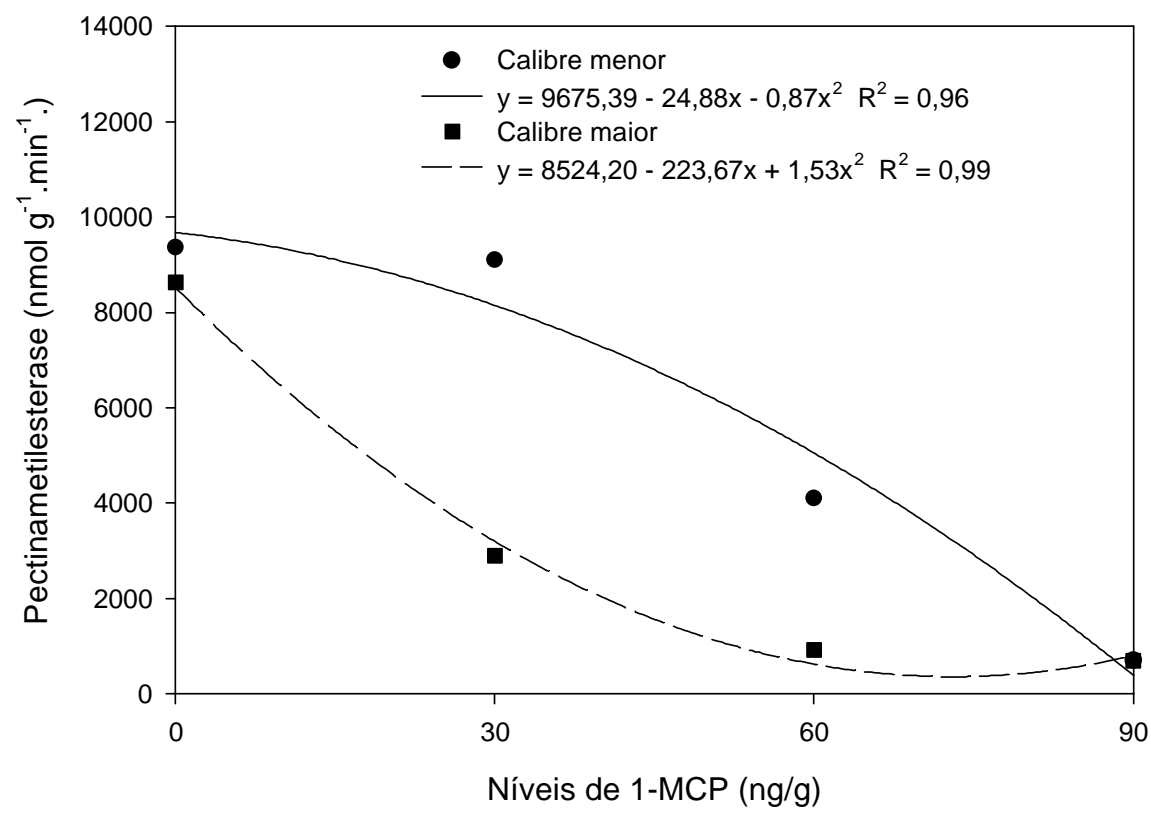

FIGURA 3 - Representação gráfica, equação de regressão e coeficiente de determinação para atividade de pectinametilesterase em bananas 'Prata-Anã' com calibre maior e calibre menor submetidas a diferentes níveis de 1MCP, climatizadas por 24 horas. 


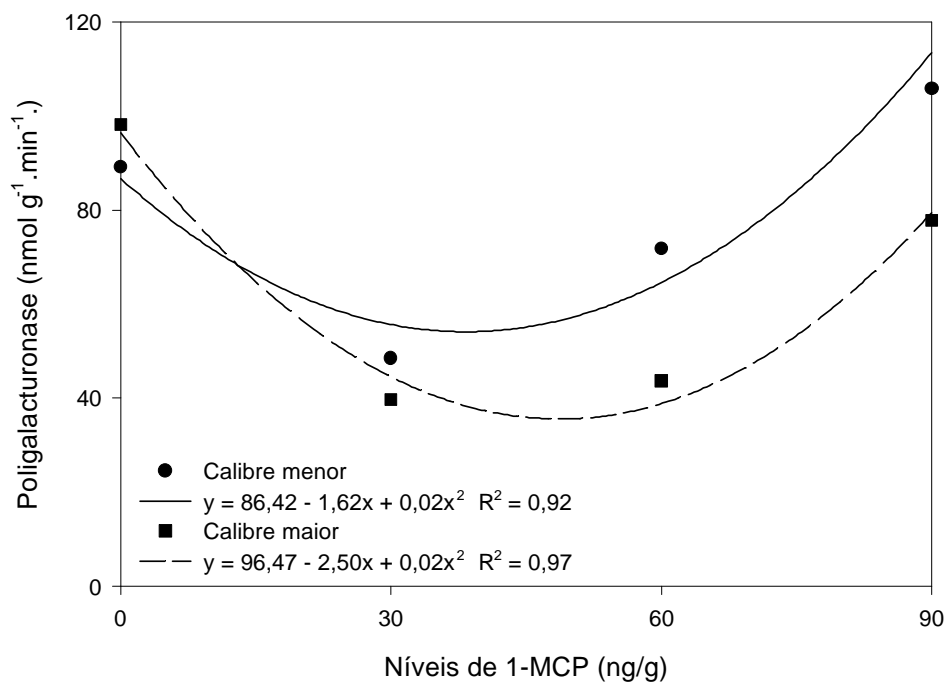

FIGURA 4 - Representação gráfica, equação de regressão e coeficiente de determinação para atividade de poligalacturonase em bananas 'Prata-Anã' com calibre maior e calibre menor submetidas a diferentes níveis de 1-MCP, climatizadas por 24 horas.

\section{CONCLUSÕES}

Sob as condições experimentais estudadas com o presente trabalho, conclui-se que:

a) Frutos tratados com 1-MCP, especialmente na dose de $60 \mathrm{ng} . \mathrm{g}^{-1}$, apresentaram reduzidos teores de pectina solúvel, porcentagens de solubilização de pectinas e menores atividades das enzimas pectinametilesterase (PME) e poligalacturonase (PG) que frutos não tratados.

b) $\mathrm{O}$ uso do $1-\mathrm{MCP}$, nas concentrações utilizadas, não impediu que o processo de amadurecimento evoluísse normalmente após a climatização dos frutos.

\section{REFERÊNCIAS BIBLIOGRÁFICAS}

AGRIANUAL. Anuário estatístico da agricultura brasileira. São Paulo: SNT, 2001. p. 194-200.

AHMAD, A. E.; LABAVITCH, J. M. Cell wall metabolism in ripening fruits. Plant Physiology, Rockville, v. 65, n. 5, p. 1009-1013, May 1980.

BITTER, V.; MUIR, H. M. A modified uronic acid carbazole reaction. Analytical Biochemistry, New York, v. 34, n. 4, p. 330-334, Apr. 1962.

BLANKENSHIP, S. Discovery and commercialization of 1-MCP as an ethylene inhibitor. Perishables Handling Quarterly, Amsterdam, n. 108, p. 5, Nov. 2001. (Special Issue).
CHITARRA, A. B. Contribuição ao estudo da fisiologia e bioquímica pós-colheita da banana 'Marmelo'. 1979. 110 f. Tese (Doutorado em Ciências dos Alimentos) - Universidade de São Paulo, São Paulo, 1979.

CHITARRA, M. I. F.; CHITARRA, A. B. Pós-colheita de frutos e hortaliças: fisiologia e manuseio. Lavras: ESAL/FAEPE, 1990. 320 p.

FENNEMA, O. R. Química de los alimentos. Zaragoza: Acribia, 1993. 1100 p.

FISHER, R. L.; BENNET, A. B. Role of cell wall hydrolases in fruit ripening. Annual Review of Plant Physiology and Plant Molecular Biology, Palo Alto, v. 46, p. 297-520, 1991.

FONSECA, H. Bioquímica de alimentos. Piracicaba: ESALQ, 1974. 249 p.

FORSYTH, W. G. C. Banana and plantain. In: NAGY, S.; SHAW, P. E. (Eds.). Tropical and subtropical fruits. Westport: Avi, 1980. 570 p.

FRY, S. C. Polyssacharide: modifying enzymes in the plant cell wall. Annual Review of Plant Physiology and Plant Molecular Biology, [S.1.], v. 46, p. 497-520, 1995. 
HARRIS, D. R. Effect of fruit maturity on efficiency of 1: methylcycloproene to delay the ripening of bananas. Postharvest Biology and Technology, New York, v. 20, p. 303-308, 2000.

HUBER, D. J. Polyuronide degradation and hemicelulose modifications in ripening tomato fruit. Journal of the American Society for Horticultural Science, Alexandria, v. 108, n. 3, p. 405-409, May 1983.

HULTIN, H. O.; LEVINE, A. S. Pectin methyl esterase in ripening banana. Journal of Food Science, Chicago, v. 30, n. 6, p. 917-920, Nov./Dec. 1965.

ISRAELI, Y.; LAHAV, E. Banana. In: MONSELISE, S. P. CRC Handbook of fruit set and development. Flórida: CRC, 1986. p. 45-73.

JEN, J. J.; ROBINSON, M. L. P. Pectolytic enzymes in sweet Bell Peppers (Capsicum annum L.). Journal of Food Science, Chicago, v. 49, n. 4, p. 1045-1087, July/Aug. 1984.

JIANG, Y.; JOYCE, D. C.; MACNISH, A. J. Extension of the shelf life of banana fruit by 1: methylcyclopropene in combination with polyethylene bags. Postharvest Biology and Technology, New York, v. 16, p. 187193, 1999

KOJIMA, K.; SAKURAI, N.; KURAISHI, B. Fruit softening in banana: correlation among stressrelaxation parameters, cell wall components and starch during ripening. Physiologia Plantarum, Copenhagen, v. 90 , n. 4, p. 772-778, Apr. 1994.

KU, V. V. V.; WILLS, R. B. H. 1-Methylcyclopropene can differencially affect the postharvest life of strawberries exposed to ethylene. Hortscience, Alexandria, v. 34, n. 1, p. 119-120, Feb. 1999a.

KU, V. V. V.; WILLS, R. B. H. Effect of 1methylcyclopropene on the storage life of brocoli. Postharvest Biology and Technology, New York, v. 17, p. 127-132, 1999b.

LIZADA, M. C. C. Ripening of banana: changes during ripening in banana. In: HASSAN, A.; PANTASTICO, E. B (Eds.). Banana fruit development postharvest physiology, handling and marketing. Boston: ASEAN, 1990. cap. 5, p. 65-84.
LIU, F. W. Banana response to low concentrations of ethylene. Journal of the American Society for Horticultural Science, Alexandria, v. 101, p. 222224, 1976.

MARKOVIC, O.; HEINRICHOVA, K.; LENKEY, B. Pectolytic enzymes from banana. Collection of Czechoslovak Chemical Communications, Prague, v. 40, n. 3, p. 769-774, 1975.

MARRIOTT, J.; PALMER, J. K. Bananas: physiology and biochemistry of storage and ripening for optimum quality. CRC Critical Review in Food Science and Nutrition, Boca Raton, v. 13, n. 1, p. 41, Jan. 1980.

McCREADY, R. M.; McCOMB, E. A. Extration and determination of total pectin materials in fruits. Analytical Chemistry, Washington, v. 24, n. 12, p. 1586-1588, Dec. 1952.

PORAT, R. Effects of ethylene and 1: methilcyclopropene on the postharvest qualities of 'Shamouti' oranges. Postharvest Biology and Technology, New York, v. 15, n. 2, p. 155-163, Feb. 1999.

PRESSEY, R.; AVANTS, J. K. Separation and characterization the exopoligalacturonase and endopolygalacturonase from peaches. Plant Phisiology, Rockville, v. 52, n. 3, p. 252-256, Sept. 1973.

PRESSEY, R.; AVANTS, J. K. Solubilization of cell walls by tomato polygalacturonase: effects of pectinesterases. Journal of Food Biochemistry, Westport, v. 6, n. 1, p. 57-74, Mar. 1982.

RATNER, A. R.; GOREN, R.; MONSELISE, S. P. Activity of pectinesterase and cellulase in the abscission zone of citrus leaf explants. Plant Physiology, Washington, v. 44, p. 1717-1723, Dec. 1969.

ROHM; HAAS. 1-Metilcilopropeno (1-MCP). [S.1.]: Agrofresh, [2002]. (Boletim Técnico).

SEREK, M.; SISTER, E. C. Novel gaseous ethylene binding inhibitor prevents effects in polled flowering plants. Journal of the Americam Society for Horticultural Science, Alexandria, v. 119, n. 6, p. 1230-1233, Nov. 1994. 
SEREK, M.; TAMARI, G.; SISTER, E. C. 1Methylcyclopropene, a novel gaseus inhibitor of ethylene action, improves the life of fruits, cut flowers and potted plants. Acta Horticulturae, Amsterdam, v. 394, p. 337-345, 1995.

TAN. Changes of the petic substances in the ripening of bananas (Musa sapientum, cultivar emas) after storage in polyethylene bags. ASEAN Food Journal, [S.1.], v. 2, n. 2, p. 76-77, 1986.

VILAS BOAS, E. V. B. Modificações pós-colheita de bananas 'Prata' (Musa acuminata X Musa balbisiana Grupo AAB) $\gamma$-irradiada. 1995. 73 f. Dissertação (Mestrado em Ciência dos Alimentos) - Universidade Federal de Lavras, Lavras, 1995. 